\title{
COMO QUERER BALBURDIAR: UM RESPIRO PARA A POÉTICA DAS VOZES
}

\author{
How to want to stir up turmoil: a breather for the poetics of voices
}

\section{Bianca Rosina Mattia}

https://orcid.org/0000-0002-0136-1241

\section{Daniela Stoll}

https://orcid.org/0000-0001-8843-779X

\section{Elton da Silva Rodrigues}

D https://orcid.org/0000-0002-1890-7482

Isabele Soares Parente

https://orcid.org/0000-0003-0561-5488

\section{Jair Zandoná}

(iD https://orcid.org/0000-0002-4301-9436

\section{Tânia Regina Oliveira Ramos}

http://orcid.org/0000-0002-2477-0419

Universidade Federal de Santa Catarina, Programa de Pós-Graduação em Literatura,

Florianópolis, SC, Brasil 88040-900 - ppglitufsc@gmail.com

Comecemos nossa breve reflexão com uma citação, uma citação-legenda que acompanha, no Instagram da artista-escritora-professora (das identidades hifenizadas tão caras a nós, tal qual nós) Telma Scherer ${ }^{1}$, professora da UFSC, um detalhe do poema-pintura Balbúrdia, um

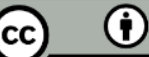

Esta obra está licenciada sob uma Creative Commons - Atribuição 4.0

\footnotetext{
1 Telma é professora de Teoria Literária na UFSC. Sua produção literária-artística pode ser acompanhada em @ telmascherer e em seu Blog. Com Squirt (Terra Redonda, 2019), é semifinalista do Prêmio Oceanos 2020. Durante o período de isolamento, neste ano, devido à pandemia da COVID-19, durante 40 dias escreveu o conjunto \#declaraçõesdesnecessárias. Como explica, "O trabalho foi desenvolvido como uma forma de experimentar a possibilidade de uma escrita site specific, dialogando, também, com o campo das artes midiáticas. O vetor inicial foi o de pensar como criar uma escrita de interface, que questionasse, a seu modo, a própria rede social. Nesse sentido, a ficcionalização da exposição da vida pessoal foi um fator de risco da empreitada, que surgiu também como resposta à situação de isolamento social vivenciada a partir das ações de combate ao novo coronavírus." Disponível em: https://telmascherer.blogspot.com/p/declaracoesdesnecessarias.html?m=0. Acesso em: 23 set. 2020.
} 
respiro (180cm x $165 \mathrm{~cm}$, técnica mista, incluindo tinta acrílica e spray sobre tecido), que ilustra o segundo número da Anuário de Literatura deste ano:

A foto da pintura não é pintura; e a própria pintura vive em mim do poema,
apenas. O que o poema declara, a mancha de tinta desdeclara, com um certo
cinismo e dor nas costas. Mas o que desdeclara o poema, o que é que dispara
nas circunvoluções da mente, o que ele dança, onde faz pausa? Essa pintura,
no fundo, é música, composta a partir dos ecos de um trompete reverberando
a infância, quando o pai espalhava seus agudos pela vizinhança. E percute os
gritos das crianças, cada martelada da perene construção ao lado da casa onde
vivo, no final de uma rua meio mal calçada, no Campeche, onde os aviões às
vezes passam, às vezes pausam. (SCHERER, 2020).

O poema-pintura, a poesia amalgamada à pintura que também se faz música, pelas cores, contornos, jogo de luz e de sombra, de sobreposições - técnica mista que exige da polissêmica composição outros modos de ler, à guisa de desdeclaração - rompe com a tradicional forma ocidental da-esquerda-para-a-direita, irrompe para alternativas, para outras rotas (e/ou de fuga) que possibilitam... um respiro. E respirar, gesto automático/mecânico do corpo também estabelece ritmo à palavra, seja lida, seja falada. A voz está intimamente ligada à palavra escrita, inscrita na memória mítica dos registros literários conhecidos, como é o caso de Tristão e seu fim trágico, que chegou por volta do século XIII à Península Ibérica, havendo menções aos personagens nos cancioneiros de lírica galego-portuguesa (ROSSI, 1979). Daí que este segundo número da Anuário traz a primeira de duas partes do dossiê "Poéticas da voz", organizados por Susan de Oliveira (UFSC) e Susana Souto Silva (UFAL), posto que os "vínculos entre voz e poesia atravessam tempos e culturas e chegam à contemporaneidade com grande vitalidade, especialmente em línguas e comunidades onde as poéticas sustentadas pela voz circulam em grande número [...] [em] homenagem a Jerusa Pires Ferreira, que foi uma grande pesquisadora das poéticas da voz, no Brasil, tendo formado muitos pesquisadores a partir, especialmente, dos trabalhos teóricos de Paul Zumthor, de quem foi tradutora." (LITERATURA, 2019, n.p). Nesse sentido, há contribuições de diferentes pesquisadoras e pesquisadores sobre o tema, provenientes da Universidade Estadual do Rio de Janeiro, da Universidade Federal do Tocantins, do Instituto Federal de Educação, Ciência e Tecnologia de Alagoas, da Universidade Federal de Santa Catarina, da Universidade de Pernambuco, da Secretaria da Educação do Estado de São Paulo, da Universidade Federal do Rio Grande do Sul e da Universidade Federal do Pará, além de contribuições de artigos com temática livre de autoras/es da Universidade Federal de Alagoas, Universidade Interamericana/Paraguai e da Secretaria de Educação e da Ciência e Tecnologia do Estado da Paraíba, bem como de uma resenha dedicada ao livro Os testamentos, de Margaret Atwood (2019), vinda da Universidade Estadual de Campinas.

Este Brasil, aqui representado por vozes afinadas pela pesquisa acadêmica, nos remete novamente à composição transdisciplinar que abre o segundo número da Anuário, arte gentilmente cedida por Telma Scherer, a quem agradecemos, que talvez (ou seria também?) se faz partitura (des)declarada de cores-formas desloca e re(des)estrutura, se (des)organiza e se reorganiza continuamente à esteira do projeto verbivocovisual. A escrita site specific ao se 
chamar Balbúrdia vem plena de sonoridades e carrega, não obstante, a potência do poema e do microconto - forma brevíssima, uma fruição literária-imagética tão certeira quanto são, por exemplo,os projetos@microcontando e@microliteratura.

Nos arriscamos a uma aproximação. Duas, na verdade: Sylvia Plath (1995), sobre poema, e Julio Cortázar (1999), acerca do conto (e não sobre microconto, mas que mesmo assim vale a pena a alusão). A poeta compara o poema, de caráter concentrado, a um punho fechado. Em comparação ao romance, de força diluída, assemelha-se a uma mão aberta, que pode, assim como as linhas das mãos, desdobrar-se em enredos para construir a trama:

Não falo dos poemas épicos. Todos sabemos o tempo que esses podem levar. Falo do pequeno poema de jardim, sem pretensões oficiais. Como hei de descrevê-lo? - abre-se uma ponta, fecha-se uma porta. Entre uma coisa e outra, entrevimos uma imagem - um jardim, uma pessoa, um aguaceiro, uma libélula, um coração, uma cidade. Estou a pensar nesses pesa-papéis redondos, de vidro, da época vitoriana, de que ainda me lembro mas nunca consigo encontrar - tão diferentes dos artigos de plástico, produzidos em série, que enchem as secção de brinquedos dos armazéns Woolworths. Esse tipo de pesapapéis é um globo transparente, um universo fechado, puro e límpido, com uma floresta, uma aldeia ou um grupo familiar lá dentro. Viramo-lo de pernas para o ar, depois tornamos a endireitá-lo. Começa a nevar. Tudo se altera no espaço de um minuto. Nada, lá dentro, voltará a ser como era - nem os abetos, nem as empenas dos telhados, nem os rostos. Assim acontece o poema. E, de facto, é tão pouco o espaço! Tão pouco o tempo! O poeta faz-se um perito em acondicionar na mala os seus pertences:

Estes rostos que surgem na multidão;

Pétalas num ramo negro de chuva.

E já está: o começo e o fim num fôlego só. Como faria o romancista a mesma coisa? Num parágrafo? Numa página? Diluindo talvez o assunto, como tinta, num pouco de água, dissolvendo-o, espalhando-o (PLATH, 1995, p. 66-67).

Tomamos, ainda, emprestada a metáfora do boxe elaborada por Julio Cortázar, ao cotejar as diferenças entre romance e conto: o romance vence o leitor por pontos; o conto, por nocaute. O mesmo ocorre com Balbúrdia, um respiro. As imagens elaboradas convocam o leitor a perscrutar nos detalhes do detalhe da foto da pintura - que não é a pintura - a potência nocauteante desse punho fechado que nos toma possível, aqui, digital e virtualmente.

Esse poema-pintura instiga a incursão pela textualidade digital e seu suporte, seja pela tela do computador, do smartphone, do tablet ou qualquer outro dispositivo, conforme Roger Chartier (2014, p. 123-124), "confronta o leitor com vários tipos de textos [os quais] podem ser produzidos ou recebidos no mesmo suporte e numa forma usualmente escolhida pelo próprio leitor." Sobre as reflexões do historiador francês, cabe destacar a discussão acerca das possibilidades próprias da nova tecnologia em inventar e oferecer formas originais de escrever - e de publicar, sem dúvida. "No reino digital, não é o objeto escrito que é dobrado, como no caso do manuscrito ou da página impressa, mas o próprio texto. Isso significa que a leitura consiste em 'desdobrar' aquela textualidade móvel e infinita." (CHARTIER, 2014, p. 125). É justamente as possibilidades de "desdobrar", mencionadas por Roger Chartier, que nos interessam. O meio digital demandou uma - ou várias - maneira/s nova/s de ler. A 
reorganização da cultura escrita com a revolução digital, possibilitando novos suportes para publicação e circulação de textos, tem motivado e constantemente atualizado os periódicos acadêmicos tal como a Anuário de Literatura.

Parece ser consenso que tratar de leitura seja um assunto bastante sensível. Não que tenha desaparecido, mas está em constante concorrência com outros tipos de textos, dos quais o virtual e o cinematográfico recebem maior destaque. Porque navegar é preciso. A internet, nesse sentido, parece fornecer o exemplo máximo da comunicação (cada vez mais) em tempo real, entre pessoas cada vez mais distantes - ou nem tanto, sobretudo em tempos em que o distanciamento social como uma das ações de combate ao novo coronavírus é peremptória - e tem se mostrado um espaço poderoso para localizar, em formatos variados (em PDF, EPUB, HTML, entre outros), textos literários ou não, que poderiam ser de difícil acesso no formato impresso.

Essa seja, talvez, a nossa novidade. Se 2020 está sendo marcado pela balbúrdia remota, resistindo e existindo como podemos, entre a lembrança do centenário de Clarice Lispector e as muitas homenagens virtuais de seu universo de pesquisadoras e leitoras, as lives, os diários de quarentena, as redes sociais, reuniões, aulas, eventos, leituras, escritas, produzindo coletivamente, finalizaremos o ano com o desafio de migrar o fluxo editorial da Anuário do formato de publicação semestral (tradicional) pelo de fluxo contínuo, o qual está sendo ou já foi implementado pelos outros periódicos abrigados no Portal de Periódicos da UFSC. A publicação de fluxo contínuo segue a lógica de que, a partir do momento em que um artigo ou um conjunto de artigos for/em aprovado/s, já pode/m seguir a tramitação editorial sem a necessidade de esperar o fechamento do número, tal como acontece até agora. Um desafio que decidimos ter a coragem de assumir, na certeza que podemos contar com a valiosa contribuição das/os pareceristas e, sem dúvida, pelo trabalho coletivo e colaborativo que faz a Anuário nascer. Retomamos, como presságio, a ideia inicial da revista, lançada em 1993, e que podemos ler na brevíssima, mas contundente, apresentação daquele número inaugural:

Exposição e troca de idéias. Painel do que se fez e se discutiu durante o ano. Espaço de manifestação de alunos e professores da Pós-graduação em Letras da UFSC. Mas não só: aberto também a contribuições outras, vindo enriquecer este espaço de debates. Eis ANUÁRIO, revista que nasce com a marca do tempo, que busca impregnar-se de seu tempo, que quer dar um som mais forte "às palavras da tribo", que quer fixar, "preto no branco", no papel, as idéias e as palavras que por aqui nasceram. Para lhes dar interlocutores. Para que se multipliquem e ecoem. Para que esse eco sirva para fazer brotar novas idéias e palavras. (LITERATURA, 1993, p. 8).

Já agora, a marca do tempo se faz virtual, digital, pixelizada, em PDF, em EPUB, publicação que não será mais semestral, mas de fluxo contínuo, receptiva às balburdias literárias e culturais de um Brasil democrático e plural. Balburdiar é a possibilidade de misturar e nunca buscar o definitivo, o conclusivo, o ponto final. Um volume por ano que acolherá as ideias, os debates e as contribuições submetidas, avaliadas pelos pares, aceitas e publicadas. A Anuário de Literatura faz parte assim das mutações para o século XXI. 


\section{Referências}

CHARTIER, Roger. A mão do autor e a mente do editor. Trad. de George Schlesinger. São Paulo: Editora UNESP, 2014.

CORTÁZAR, Julio. Alguns aspectos do conto. In: CORTÁZAR, Julio. Obra crítica. Trad. de Pualina Wacht e Ari Roitman. Rio de Janeiro: Civilização Brasileira, v. 2, 1999. p. 345-363.

LITERATURA, Anuário de. Apresentação. Anuário de Literatura, Florianópolis, p. 01-08, jan. 1993. Disponível em: https://periodicos.ufsc.br/index.php/literatura/article/view/5227/4651. Acesso em: 25 set. 2020.

LITERATURA, Anuário de. Chamada v. 25, n. 2 (2020). Florianópolis (Santa Catarina), 04 nov. 2019. Facebook: @anuariodeliteratura. Disponível em: https://www.facebook.com/anuariodeliteratura/photos/basw.AbrUt8mAyJf9IE_qYMwqgrdA0 z5G5HImD3SvhXh12vhUCNEhZgbDWaRt4fLwbWkX5v_TGzBT_x1NgyhbypILXyx4IQed Ps0uFJf-

ZwWoaF38A6RsBmW2HtaR4eCVL1J4JIhU9M17Mn1QGq6s9q81QbBxfWUEIBoxDuAm4i qeXD8iQ/1566020090207432. Acesso em: 25 set. 2020.

PERRONE-MOYSÉS, Leyla. Mutações da literatura no século XXI. São Paulo: Companhia das Letras, 2016.

PLATH, Sylvia. Uma comparação. In: PLATH, Sylvia. Zé Susto e a Bíblia dos Sonhos. Trad. de Ana Luísa Faria. Lisboa: Relógio D’Água, 1995. p. 65-68.

ROSSI, Luciano. A Literatura Novelística na Idade Média Portuguesa. Amadora Portugal: Instituto de Cultura Portuguesa, 1979.

SCHERER, Telma. A foto da pintura não é pintura. Florianópolis (Santa Catarina), 23 ago. 2020. Instagram: @telmascherer. Disponível em: https://www.instagram.com/p/CEO4iP4ADVs/. Acesso em: 23 set. 2020.

\section{NOTAS DE AUTORIA}

Bianca Rosina Mattia (biancamattia@gmail.com) é doutoranda em Literatura no Programa de Pós-Graduação em Literatura da UFSC. Mestra em Literatura (PPGLit/UFSC). Licenciada em Letras-Língua Portuguesa e Literaturas (UFSC). Bacharela em Ciências Jurídicas e Sociais (UPF). Integra o quadro discente do Núcleo de Literatura Atual - Estudos Feministas e PósColoniais de Narrativas da Contemporaneidade (LITERATUAL/UFSC). Compõe a Comissão Editorial da revista Anuário de Literatura e tem interesse em Literatura Portuguesa (séc. XX e XXI) e Estudos Literários sob a perspectiva dos Estudos de Gênero e da Crítica Feminista.

Daniela Stoll (sstolldaniela@gmail.com) é doutoranda em Literatura no Programa de PósGraduação em Literatura da Universidade Federal de Santa Catarina (UFSC) e Mestra em Literatura pela mesma universidade (2017). É membro da comissão editorial da Revista Anuário de Literatura (PPGL/UFSC) e integrante do Núcleo Literatual. Graduou-se em Arquitetura e Urbanismo (UFSC, 2010) e desde 2018 cursa a graduação em Letras, Língua 
Portuguesa e Literaturas, também na UFSC. É autora do romance Do lado de dentro do mar (Editora Patuá, 2018).

EIton da Silva Rodrigues (eltonrodriguesdsr@gmail.com) é licenciado em Letras - Língua Portuguesa e Literatura pela UFSC e integrante do LabFlor: Laboratório Floripa em composição transdisciplinar: arte, cultura e política. Mestrando em Literatura pelo Programa de PósGraduação em Literatura da Universidade Federal de Santa Catarina (UFSC) e bolsista CNPq.

Isabele Soares Parente (isabele.soares.p@gmail.com) é mestranda em Literatura pela UFSC. Possui graduação em Letras - Língua Portuguesa pela Universidade Regional do Cariri (URCA). É pesquisadora do Núcleo de Estudos em Teoria Linguística e Literária (NETLLI) e participa do Laboratório de Estudos de Gênero e História (LEGH) e do Núcleo de Pesquisa em Cultura Popular Behetçoho. Possui interesse nos temas: estudos feministas e pós-coloniais, narrativas contemporâneas e cultura popular.

Jair Zandoná (jzandona@gmail.com) realiza estágio de pós-doutorado no Programa de PósGraduação em Linguística da UFSC com bolsa PNPD/CAPES. Doutor e mestre em Literatura pela mesma instituição. É um dos editores da Revista Anuário de Literatura (PPGL/UFSC) e editor de resenhas da Revista Estudos Feministas (REF). Integra o quadro de pesquisadores/as do Instituto de Estudos de Gênero/UFSC, do Literatual/UFSC e do Grupo de Estudos no Campo Discursivo/UFSC.

Tânia Regina Oliveira Ramos (taniareginaoliveiraramos@gmail.com) possui graduação em Letras pela UFSC, mestrado e doutorado em Literaturas de Língua Portuguesa pela PUC-RJ. Atualmente é Professora Titular e coordena o núcleo Literatura e Memória da UFSC. Faz parte da Coordenação Geral da Revista Estudos Feministas. É professora de Literatura Brasileira e Estudos Literários nos Cursos de Graduação e Pós-Graduação em Letras e Literatura na UFSC. Atua, pesquisa e publica nas linhas de pesquisa História e Memória, escritas de si e gênero.

\section{Como citar esse artigo de acordo com as normas da revista}

MATTIA, Bianca Rosina; STOLL, Daniela; RODRIGUES, Elton da Silva; PARENTE, Isabele Soares; ZANDONÁ, Jair; RAMOS, Tânia Regina Oliveira. Como querer balburdiar: um respiro para a poética das vozes. Anuário de Literatura, Florianópolis, v. 25, n. 2, p. 08-14, 2020.

\section{Contribuição de autoria}

Elaboração e contribuição coletiva.

\section{Financiamento}

Não se aplica.

\section{Consentimento de uso de imagem}

Não se aplica.

\section{Aprovação de comitê de ética em pesquisa}

Não se aplica.

\section{Licença de uso}

Este artigo está licenciado sob a Licença Creative Commons CC-BY. Com essa licença você pode compartilhar, adaptar, criar para qualquer fim, desde que atribua a autoria da obra. 


\section{Histórico}

Recebido em: 16/08/2020

Aprovado em: 23/08/2020

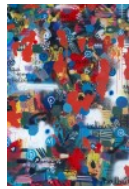

